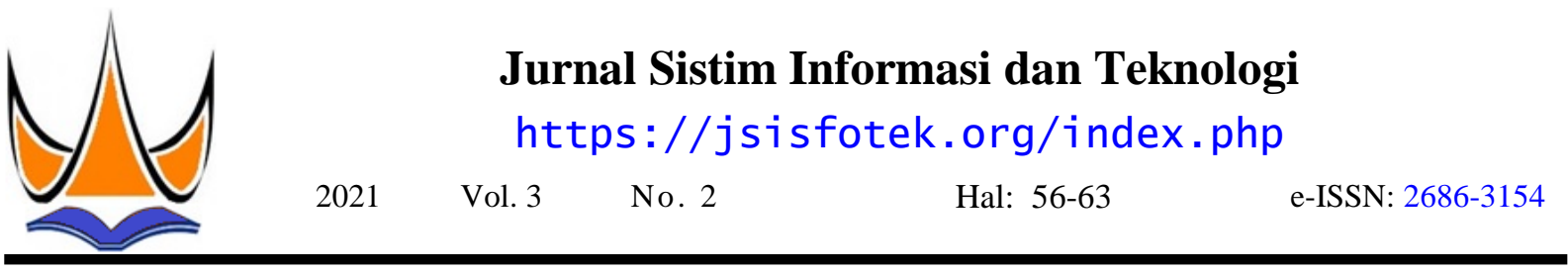

\title{
Meningkatkan Keamanan Web Menggunakan Algoritma Advanced Encryption Standard (AES) terhadap Seragan Cross Site Scripting
}

\author{
Yendi Putra $^{1 凶}$, Yuhandri Yunus ${ }^{2}$, Sumijan $^{3}$ \\ ${ }^{1,2,3}$ Universitas Putra Indonesia YPTK Padang \\ yendiputraraorao@gmai1.com
}

\begin{abstract}
In the millennial era, the internet has become a very basic need to support community activities in various fields, one of which is education. SMK Maritim Nusantara in supporting the learning process uses a web-based application called elearning which is used by teachers and students. The school website has several documents in digital form that must be kept confidential, such as student data, teacher data, student grades. After scanning using the Acunetix WVS 10.5 application, information was obtained about the security holes found on the website https://www.e-learning.smkmn.sch.id, with the results of which there were 8 (eight) attacks with details, 2 (two). ) a hight category with the name Cross site scripting (XSS) attack, 4 (four) medium categories with the name HTML form attack without CSRF protection and 2 (two) low categories with the name Password type input attack with auto-complete enabled. The most dangerous attack category / hight is XSS. XSS attack is an attack that inserts malicious code in the form of javascript through an input form that aims to steal cookies and then uses the cookie to enter the web legally so that data can be manipulated and even deleted. For this reason, a strong system is needed to maintain security, confidentiality of school data, one way that can be used is by implementing the Standard Advance Encryption Algorithm (AES), this algorithm has a high level of security and uses little memory in its operation so that it does not burdensome to process and easy to implement. The results of research conducted by applying the AES Algorithm explain that previously there were 2 (two) high category vulnerabilities called XSS attacks, after the implementation of the AES Algorithm, the XSS attack vulnerability was no longer found. Based on the results obtained in the study, it can be concluded that the implementation of the AES Algorithm in tokens can improve the security of the https://www.e-learning.smkmn.sch.id website from XSS attacks.
\end{abstract}

Keywords: AES Algorithm, XSS, Token, Security, E-learning.

\begin{abstract}
Abstrak
Pada era milenial internet menjadi sebuah kebutuhan yang sangat mendasar guna menunjang aktifitas masyarakat dalam berbagai bidang salah satunya bidang pendidikan. SMK Maritim Nusantara dalam menunjang proses pembelajaran mengunakan aplikasi berbasis web dengan nama e-learning yang digunakan oleh guru dan siswa. Website sekolah memiliki beberapa dokumen dalam bentuk digital yang harus di jaga kerahasianya seperti data siswa, data guru, nilai siswa. Hasil scaning dari aplikasi Acunetix WVS 10.5 diperoleh informasi tentang celah keamanan yang terdapat pada website https://www.e-learning.smkmn.sch.id, dengan hasil diantaranya terdapat 8 (delapan) serangan dengan rincian, 2 (dua) kategori hight dengan nama serangan Cross site scripting (XSS), 4 (empat) kategori medium dengan nama serangan HTML form without CSRF protection dan 2 (dua) kategori low dengan nama serangan Password type input with auto-complete enabled. Kategori serangan yang paling berbahaya/hight yaitu XSS. Serangan XSS adalah serangan yang menyisipkan kodekode jahat berbentuk javascript melalui form input yang bertujuan untuk mencuri cookie lalu menggunakan cookie tesebut untuk masuk kedalam web secara sah sehingga data dapat dimanipulasi bahkan dihapus. Untuk itu dibutuhan sebuah sistem yang kuat untuk menjaga keamanan, kerahasiaan data-data sekolah, salah satu cara yang dapat digunakan adalah dengan penerapan Algoritma Advance Enkripiton Standart (AES), algoritma ini memiliki tingkat keamanan yang tinggi serta menggunakan memori yang sedikit dalam pengoperasianya sehingga tidak membebani proses dan mudah untuk diterapkan. Hasil penelitian yang dilakukan dengan menerapkan Algoritma AES mejelaskan bahwa sebelumnya terdapat 2 (dua) kerentanan kategori hight dengan nama serangan XSS, setelah implementasi Algoritma AES maka kerentanan serangan XSS tersebut tidak ditemukan lagi. Berdasarkan hasil yang diperoleh dalam penelitian dapat disimpulkan bahwa Implementasi Algoritma AES pada token dapat meningkatkan keamanan website https://www.e-learning.smkmn.sch.id dari serangan XSS.
\end{abstract}

Kata Kunci : Algoritma AES, XSS, Token, Keamanan, E-learning.

(C) 2021 JSisfotek

\section{Pendahuluan}

Cybercrime adalah tindak kejahatan yang dilakukan dengan memanfaatkan teknologi komputer sebagai alat kejahatan utama yang memanfaatakan perkembangan teknologi komputer khususnya internet. Menurut laporan dari Acunetix Web Application Vulnerability tahun 2019, serangan yang terjadi di dunia pada tahun 2019 dari total $100 \%$ serangan terdapat $25 \%$ serangan dengan menggunakan metode Cross Site Scripting (XSS) dengan rincian sebagai berikut: serangan pada Angular JS Template Injection sebesar $0.52 \%$, ikuti dengan serangan DOM XSS sebesar $1,23 \%$ dan sisanya XSS $24.5 \%$. Dengan melihat jumlah serangan tersebut maka website-website cukup rentan terhadap serangan. Sedangkan di Indonesia menurut Badan Sandi Siber Negara terdapat 88 juta serangan dalam

Diterima: 16-10-2020 | Revisi: 31-10-2020 | Diterbitkan: 30-06-2021 |DOI: 10.37034/jsisfotek.v3i2.44 
rentang waktu 4 bulan terakhir dari januari sampai april kurang efektif, langkah yang lebih efektif yaitu 2020, salah satu serangan menargetkan para penguna menggunakan autentikasi token [7].

web aplikasi.

Token berfungsi untuk mengakses halaman tertentu,

Pada umumnya sekolah-sekolah menggunakan website pengguna akan mengirim balik token tersebut sebagai sebagai media informasi dan media pendukung proses bukti bahwa pengguna sudah berhasi login, apabila belajar mengajar. Tetapi website yang ada di sekolah- tidak cocok maka akan keluar perintah dan apabila sekolah belum memiliki tingkat kemanan atau proteksi cocok maka data bisa diproses [8]. Agar lebih kuat yang kuat, sehingga menimbulkan peluang kejahatan token tersebut dilakukan enkripsi dengan menggunakan pencurian dan manipulasi data sekolah, siswa serta Algoritma dari Rijndael bernama Advanced Encryption guru untuk mendapatkan keuntungan oleh pelaku. SMK Standard. Algoritma AES mempunyai 3 jenis panjang Maritim Nusantara merupakan sekolah menengah kunci diantaranya 127, 192 dan 256, serta mempunyai kejurusan bidang kemaritiman yang berada di pesisir panjang blok 128 bit [9]. Algoritma AES berfungsi pantai Kabupaten Padang Pariaman, dalam mendukung untuk enkripsi dan deskripsi informasi atau data, proses pembelajaran SMK maritim nusantara dengan menggunakan roude atau kegiatan yang, selain menggunakan aplikasi berbasis web yaitu https://e- itu $A E S$ lebih mudah diterapkan, pengunaan memori learning.smkmn.sch.id/, yang dapat diakses oleh semua relative rendan serta efisien dari segi [10]. Teknik siswa dan guru. Pada website sekolah terdapat data- menggunakan gabungan dua metode antara data penting sekolah seperti data siswa, guru, Steganografi LSB dengan Algoritma AES. Hasil pembelajaran dan data nilai siswa. Setelah penulis penelitian ini menitik beratkan pada aspek melakukan observasi hasilnya menunjukan bahwa imperceptibility dan recovery terhadap metode website sekolah ini memiliki celah kerentanan yang modifikasi LSB yang bertujuan untuk meningkatkan dapat merugikan sekolah seperti pencurian atau keamanan dari data [11]. Sedangkan penelitian yang modifikasi data siswa, guru, pembelajaran dan data dilakukan dalam meningkatkan keamanan apalikasi enilai siswa yang dapat disalah gunakan oleh peretas. commrce dengan menerpakan Algoritma AES pada Jenis serangan yang ditemuka berupa XSS.

XSS ialah serangan dengan menyuntikan atau menyisipkan code-code jahat berbentuk javascript melalui form input yang bertujuan untuk mencuri cookie lalu menggunakan cookie tesebut untuk masuk kedalam web secara sah [1]. XSS memiliki 3 kategori diantaranya, DOM-Based XSS cara kerja dengan memanfaatkan javascript untuk memanipulasi objek model, yang berikutnya Stored On Presistent XSS bekerja dengan menyintikan javascript ke server dan disimpan permanen dalam database dan yang terakhir mengunakan teknik memantulkan kode berbahaya ke browser yang digunakan korban, cara ini disebut dengan Refected Non-Persisent XSS [2], [3]. Apabila hal ini dibiarkan maka akan mendapatkan masalah besar karena bocornya data sekolah ke pihak yang tidak bertanggung jawab. Untuk mengatasi masalah ini dapat cegah dengan menambahkan function php yaitu strip_tag, cara kerjanya dengan menghapus tag html yang menempel pada form inputan tersebut, sehingga script XSS tidak di proses melainkan di tampilkan dalam bentuk teks biasa [4]. Functian strip_tag juga digunakan pecegahan dapat juga dilakukan dengan pembatasan pada alphanumeric Features berupa pembatasan pada Readability, Objects, Events, Methods, Tags, Attributes, Reserved, Functions, Protocol, Letters, Numbers [5]. Pencegahan dari serangan XSS juga dapat digunakan dengan menggunakan metacharacter khusus yang digunakan dalam sebuah script, selain itu fungsi html_specialchars() dapat digunakan untuk merubah format HTML diantaranya: 1) \& (ampersand) menjadi \&amp, 2) single quote menjadi \&\#039, 3) (double quote) menjadi \& quo [6]. Namun cara diatas masih data costomer [12]. Hasil penelitan menjelaskan Algoritma AES pada database lebih aman karena data rahasia dienkripsi dengan mengukan key 128 dan 10 round sehingga sulit untuk dipecahkan serta memiliki kecepatan tinggi karena menggunakan memori yang kecil. Maka, penelitian ini bertujuan mengukur tingkat keamanan website e-learning SMK Maritim Nusantara dari serangan XSS selanjutnya implementasi Algoritma AES pada token untuk meningkatkan keamanan website.

\section{Metodologi Penelitian}

Langkah-langkah yang diambil penulis dalam penelitian ini tidak melenceng dari pokok pembahasan dan lebih mudah dipahami, maka susunan langkahlangkah dibuat secara sistematis sehingga mudah dijadikan pedoman. Urutan langkah-langkah yang akan dikerjakan pada penelitian ini dapat dilihat pada Gambar 1.

Jurnal Sistim Informasi dan Teknologi Vol. 3 No. 2 (2021) 56-63 


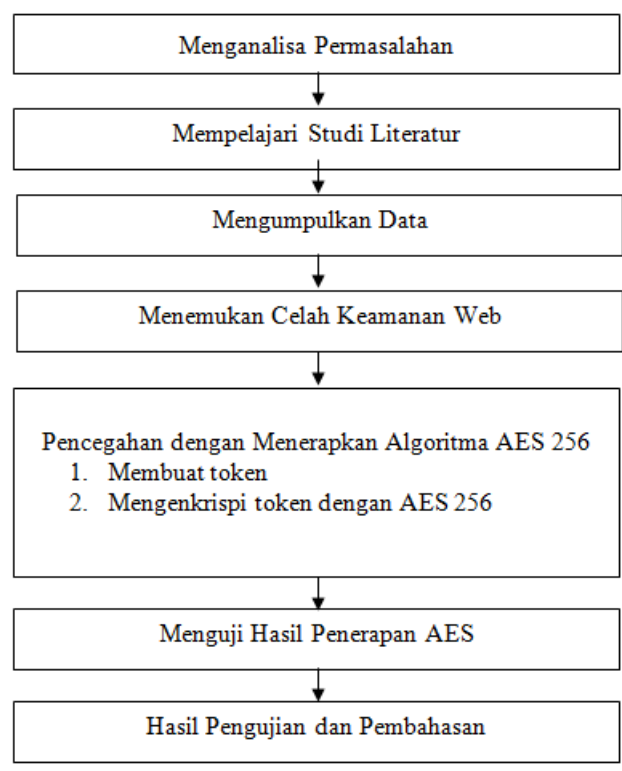

Gambar 1. Kerangka Kerja Penelitian

Algorimtma AES pada website e-learning SMK Maritim Nusantara. Hasil dari penerapan Algorima $A E S$ tersebut akan dibandingkan dengan data-data sebelum penerapan Algoritma AES.

\subsection{Data}

Pada aplikasi e-learning menggunakan server yang disewa pertahun pada penyedia layanan hosting dewaweb.com. Berikut ini data rinci server dan hosting e-learning SMK Maritim Nusantara dapat dilihat pada Tabel 1

Tabel 1. Data Rinci Server Dan Hosting E-Learing SMK Maritim Nusantara

\begin{tabular}{cll}
\hline No & \multicolumn{1}{c}{ Nama } & \multicolumn{1}{c}{ Keterangan } \\
\hline 1. & Penyedia Layanan Hosting & Dewaweb.com \\
2. & Nama paket layanan & Cloud hosting warior \\
3. & Teknologi Server & LiteSpeed \\
4. & Storage & $3 \mathrm{~GB}$ \\
5. & Kecepatan CPU & $1 \mathrm{Core}$ \\
6. & Memory & $512 \mathrm{Mb}$ \\
7. & Addon domain & 6 \\
8. & IP & 104.24 .110 .244 \\
9. & Tanggal aktif & 14 Maret 2019 \\
10 & Tanggal nonaktif & 13 Maret 2021 \\
11. & Database & Mysql \\
12. & Bahasa Pemrograman & PHP \\
13. & Domain ID & PANDI-DO1298761 \\
14. & CDN & Cloudflare \\
\hline
\end{tabular}

Uraian kerangka kerja adalah penjabaran secara rinci tentang masing-masing kerang kakerja yang telah disusun agar penelitian yang dilakukan terstruktur. Berdasarkan Gambar 1 dari kerangka kerja diatas, maka masing-masing tahapan dapat dijelaskan sebagai berikut:

a. Menganalisa Permasalahan bertujuan agar 2.2. Cross Site Scripting penelitian yang akan dilakukan dapat memahami Cross site scripting disingkat (XSS) adalah jenis masalah yang telah ditentukan batasan masalahnya.

b. Mempelajari Literatur dilakukan agar mempunyai landasan baik secara teoritis yang benar dan jelas yang telah dijelaskan oleh para peneliti dan ahli sebelumnya.

kerentanan yang terjadi pada sebuah web dinamis karena web yang dibangun tidak bisa memfilter masukan yang dikirim oleh penyerang, sehingga penyerang dengan mudah menginjeksi atau menyuntikan code jahat berupa javascript pada halaman web dengan tujuan untuk mendapatkan cookie

c. Mengumpulkan data dilakukan untuk dapat dan session untuk digunakan sebagai hak akses yang memperoleh informasi data-data yang dibutuhkan sah kedalam situs tersebut[3]. Cara Kerja Serangan XSS dalam penelitian rangka mencapai tujuan Gambar 2. penelitian.

d. Menemukan celah keamanan Web dengan melakukan scaning mengunakan aplikasi acunetix, pada penelitian ini peneliti hanya melakukan pengaman website dari serangan XSS.

e. Pencegahan dengan menerapkan Algoritma AES, Langkah-langkah yang dilakukan dalam adalah sebagai berikut:

- Membuat token dengan menggunakan fungsi dari Base64Encode dan gabungan antara header, playload dan signature [13];

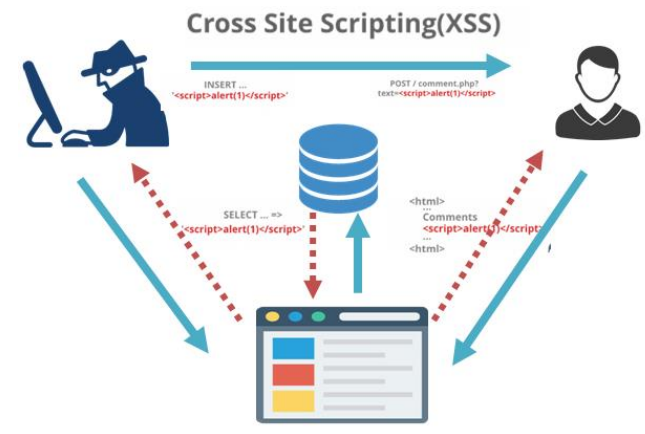

Gambar 2. Cara Kerja Serangan XSS

- Mengenkrispi token dengan Algoritma AES agar serangan dari XSS bisa dihindari.

f. Menguji Hasil Penerapan Algoritma AES pada serta signature, antara bagian satu dan lainya website e-learning SMK Maritim Nusantara dihubungkan dengan titik (“.”) diantaranya [14]: dengan menggunakan Aplikasi Acunetix.

g. Hasil Pengujian dan Pembahasan menjelaskan tentang hasil dari penerapan dan pengujian

Jurnal Sistim Informasi dan Teknologi Vol. 3 No. 2 (2021) 56-63 


\section{a. Header}

Header terdiri memiliki dua komponen, yaitu Algoritma hashing seperti HMAC SHA-256 serta tipe token.

\section{b. Payload}

Payload ialah bertugas untuk menjelaskan tentang metadata atau suatu entitas. Terdapat tiga jenis klaim, yaitu private, public, dan reserved.

\section{c. Signature}

Signature berisi hash terdiri dari komponen-komponen header, payload serta kunci rahasia.

Token yang dihasilkan dari JWT dibangun dengan menggunakan rumus atau formula sebagai berikut [15]:

Token $=\mathrm{f}($ Base64Encode $) \sum_{\mathrm{n}=\alpha, \beta}^{\infty}$ (header, playoad, signature $)$ Dimana:

$$
\begin{aligned}
\mathrm{f}(\text { Base64Encode })= & \text { Fungsi untuk melakukan } \\
& \text { penyandian dengan Base64Encode } \\
\sum_{\mathrm{n}=\alpha, \beta}^{\infty} & \text { Perulangan penjumlahan bilangan }
\end{aligned}
$$

(header, playoad, signature) $=$ Bagian kepala, bagian data, bagian kunci

\subsection{Advanced Encription Standard (AES)}

Kriptografi terdiri dari dua suku kata yaitu (kryptos) yang bermakna rahasia dan (graphein) yang bermakna tulisan, jadi kriptografi memiliki makna tulisan rahasia (Mollin, 2007).

Kriptografi dikelompokan menjadi dua diantaranya berdasarkan kunci yang digunakan, yaitu algoritma simetri (mengunakan satu kunci untuk proses enkripsi dan dekripsi), sedangkan Algoritma asimetri (memiliki kunci yang berbeda saat proses enkripsi dan dekripsi serta fungsi hash (Ariyus, 2008) [16]. Sedangkan karakteristik kriptografi digolongkan menjadi dua bagian yaitu berdasarkan tipe operasi pada enkripsi dan dekripsi (teknik substitusi dan teknik permutasi) selain itu proses pengolahan pesan berupa block chipher dan stram chipher.

Pada tahun 1998 diadakan sayembara NIST untuk melahirkan kriptografi baru untuk menganti Algoritma DES. Standard tersebut nantinya akan diberi nama Advanced Encription Standart (AES). Adapun syarat untuk sebuah AES ialah seluruh rancangan bersifat public. NIST memilih 5 finalis yang memenuhi syarat dari 15 proposal yang masuk, setelah itu dilakukan voting dan hasilnya Rijndael Vincent Rijmen dan Joan Daemen Belgia, dinobatkan sebagai pemenang dengan 86 suara. Pada tahun 2001 tepatnya bulan november, NIST mengumumkan bahwasanya Rijndael (dibaca: Rhine-doll) ditetapkan sebagai standard kriptografi sah dan dapat digunakan. Laila Mustika, (2019) Algoritma AES menggunakan substitusi dan permutasi serta sejumlah putaran, setiap putaran memiliki kunci internal yang berbeda disebut dengan round key dan beroperasi dalam orientasi byte.

Algoritma Advance Enkription Standart

a. AddRoundKey

b. Round

- SubBytes

- ShiftRows

- MixColumns

- AddRoundKey

c. Final round

- SubBytes

- ShiftRows

- AddRoundKey

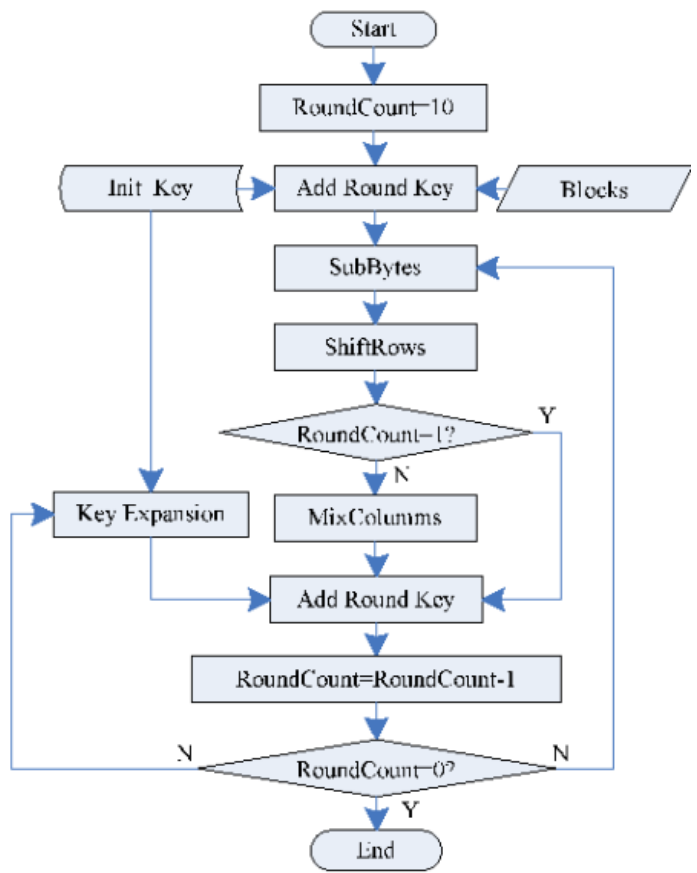

Gambar 3. Flowchart Algoritma AES

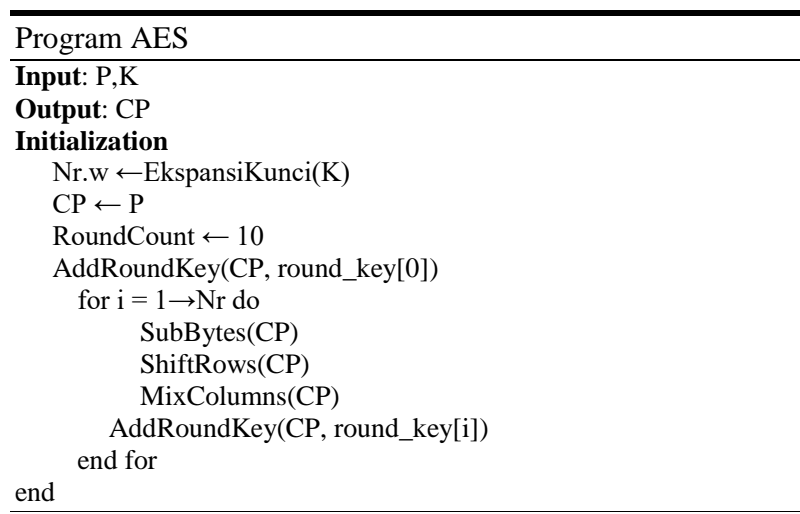
Gambar 4. Algoritma AES

\section{Hasil dan Pembahasan}

Analisa kerentanan dalam penelitian ini dilakukan dengan melakukan scaning pada website e-learning SMK Maritim Nusantara dengan menggunakan aplikasi 
Acunetix Web Vulnerability Scanner 10.5. Cara kerja token untuk otentikasi, agar token lebih kuat maka aplikasi Acunetix disajikan pada Gambar 2. dilakukan engkripsi mengunakan algoritma AES

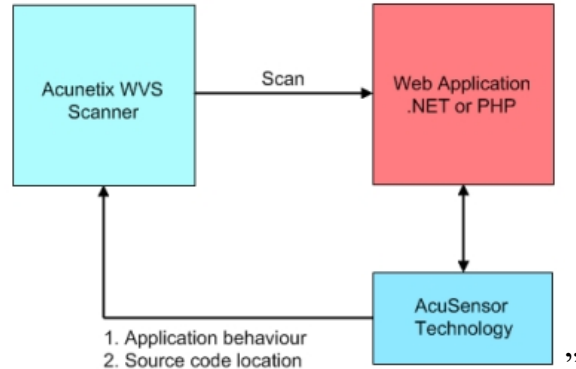

Gambar 5. Cara Kerja Aplikasi Acunetix

Hasil dari proses scaning website e-learning SMK Maritim Nusantara menggunakan aplikasi Acunetix memberikan beberpa informasi diantaranya terlihat pada Gambar 3.

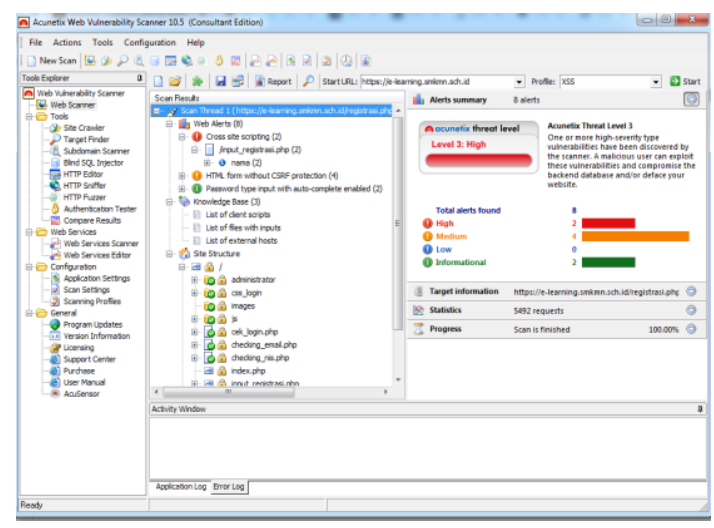

Gambar 6. Hasil Scaning web e-learning SMK Maritim mengunakan Aplikasi Acunetix

Tabel 2. Data Rincian Hasil Scaning Web e-learning Menggunakan Aplikasi Acunetix

\begin{tabular}{clll}
\hline No & \multicolumn{1}{c}{ Indikasi File } & \multicolumn{1}{c}{ Kerentanan } & $\begin{array}{c}\text { Kategori } \\
\text { Resiko }\end{array}$ \\
\hline 1. & linput_registrasi.php. & Cross site scripting & Hight \\
nama & /input_registrasi.php & Cross site scripting & Hight \\
2. & nama & HTML form without & Medium \\
3. & ladministrator. & $\begin{array}{l}\text { CSRF protection } \\
\text { HTML form without }\end{array}$ & Medium \\
4. & /login.php & $\begin{array}{l}\text { CSRF protection } \\
\text { HTML form without }\end{array}$ & Medium \\
5. & /registrasi.php & $\begin{array}{l}\text { CSRF protection } \\
\text { HTML form without }\end{array}$ & Medium \\
6. & /login.php & $\begin{array}{l}\text { CSRF protection } \\
\text { Password type input } \\
\text { with auto-complete }\end{array}$ & Low \\
7. & ladministrator.php & $\begin{array}{l}\text { enabled } \\
\text { Password type input } \\
\text { with auto-complete } \\
\text { enabled }\end{array}$ & Low \\
8. & /login.php & & \\
& & &
\end{tabular}

\subsection{Pembuatan Token}

Token terdiri dari tiga bagian diantarnya. header, playload dan signature, ketiga komponen ini di encode mengunakan base64encode lalu digabungkan menjadi satu dengan tanda (.) titik sebagai pemisah. Cara pembautan token sebagai berikut

a. Pembuatan Header

\{

"typ": "JWT",

"alg": "HS256"

\}

Hasil dari encode mengunakan base64encode pada header adalah "eyJhbGciOiJIUzI1NiIsInR5cC I6IkpXVCJ9"

b. Pembuatan Playload

\{

"sub": "1234567890",

"name": "John Doe",

"iat": 1516239022

\}

Hasil dari encode mengunakan base64encode pada playload adalah eyJzdWIiOiIxMjM0NTY3ODk wIiwibmFtZSI6IkpvaG4gRG91IiwiaWF0IjoxNTE 2MjM5MDIyfQ"

c. Signature dihasilkan dari pengabunga header dan playload dengan penambahan secret key untuk mengamankan token, secret key yang dimasukan adalah "sanditokenaes128". Hasil dari encode adalah "goeCWV2u8ee5-gqj-L0B6Y9YgIZcfM KY2Ad2Lv4V-c”

JWT dihasilkan dengan mengabungkan header, playload dan signature dimana secretkey yang digunakan adalah ="sanditokenaes128" . hasilnya sebagai berikut."eyJhbGciOiJIUzI1NiIsInR5cCI6Ikp XVCJ9.eyJzdWIiOiIxMjM0NTY3ODkwIiwibmFtZSI6 IkpvaG4gRG91IiwiaWF0IjoxNTE2MjM5MDIyfQ.goe CWV2u8ee5-gqj-2L0B6Y9YgIZcfMKY2Ad2Lv4V-c"

\subsection{Implementasi Algoritma AES Pada Secret Key} Token

Token yang telah dibuat mengunakan JWT agar lebih kuat dilakukan enkripsi mengunakan Algoritma AES dimana secretkey menjadi plaintext pada Algoritma $A E S$. Adapun langkah-langkah sebagai berikut.

Terlebih dahulu ditetapkan secretkey sebagai plaintext, lalu ditetapkan

Plaintext : sanditokenaes 128

Cipherkey : kuncirahasiantim

Hasil scaning menunjukan bahwa terdapat 2 (dua) Konversikan plaintext dan cipherkey text dari ASCII ke kerentanan dengan level hight yaitu serangan Cross Site hexadecimal lalu disimpan pada array of bytes dua Script, serangan ini sangat berbahaya sehingga harus di dimensi yang berukuran 4 x 4 . Data masukan, in0, in1, antisipasi, cara mengatasinya dengan mengunakan ..., in15 disalin ke dalam array state (direalisasikan

Jurnal Sistim Informasi dan Teknologi Vol. 3 No. 2 (2021) 56-63 
oleh fungsi CopyPlaintext ToState(state, plaintext)) seperti Tabel 3.

Tabel 3. Konvesi Plaintext dan Cipherkey dari ASCII ke Hexadecimal

\begin{tabular}{cccc}
\hline \multicolumn{4}{c}{ Plaintext } \\
\hline 73 & 69 & 65 & 73 \\
61 & 74 & $6 \mathrm{e}$ & 31 \\
$6 \mathrm{e}$ & $6 \mathrm{f}$ & 61 & 32 \\
64 & $6 \mathrm{~b}$ & 65 & 38 \\
\hline
\end{tabular}

\begin{tabular}{cccc}
\hline \multicolumn{4}{c}{ Cipherkey } \\
\hline $6 \mathrm{~b}$ & 72 & 73 & 74 \\
75 & 61 & 69 & 74 \\
$6 \mathrm{e}$ & 68 & 61 & 69 \\
69 & 61 & $6 \mathrm{e}$ & $6 \mathrm{~d}$ \\
\hline
\end{tabular}

a. AddRoundKey yaitu melakukan XOR antara plainteks dengan cipherkey

\begin{tabular}{|c|c|c|c|c|c|c|c|}
\hline \multicolumn{4}{|c|}{ Plaintext } & \multicolumn{4}{|c|}{ Cipherkey } \\
\hline 73 & 69 & 65 & 73 & $6 b$ & 72 & 73 & 74 \\
\hline 61 & 74 & $6 \mathrm{e}$ & 31 & 75 & 61 & 69 & 74 \\
\hline $6 e$ & $6 f$ & 61 & 32 & $6 \mathrm{e}$ & 68 & 61 & 69 \\
\hline 64 & $6 b$ & 65 & 38 & 69 & 61 & $6 \mathrm{e}$ & $6 d$ \\
\hline
\end{tabular}

\begin{tabular}{cccc}
\hline \multicolumn{4}{c}{ Key Adition } \\
\hline 18 & $1 \mathrm{~B}$ & 16 & 07 \\
14 & 15 & 07 & 45 \\
00 & 07 & 00 & $5 \mathrm{~B}$ \\
$0 \mathrm{D}$ & $0 \mathrm{~A}$ & $0 \mathrm{~B}$ & 55 \\
\hline
\end{tabular}

b. Round yaitu melakukan putaran dimana $\mathrm{Nr}-1$ kali. Proses yang dikerjakan pada setiap putaran adalah

a. SubBytes yaitu melakukan substitusi mengunakan tabel (S-box).

Tabel 5. SubBytes mengunakan Tabel S-BOX

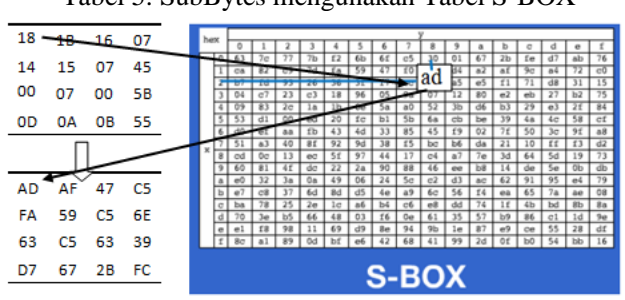

b. ShiftRows yaitu pergeseran secara wrapping (siklik) pada 3 baris terakhir dari array state, jumlah geseran tergantung nilai baris(r) dimana $r=1$ digeser 1 byte kekiri, $r=2$ digeser 2 byte kekiri, $\mathrm{r}=3$ digeser 3 byte kekiri sedangkan $\mathrm{r}=0$ tidak digeser, hasil pergeseran seperti tabel 5

Tabel 6. ShiftRows Array State

\begin{tabular}{|c|c|c|c|c|c|c|c|}
\hline $\mathrm{AD}$ & $\mathrm{AF}$ & 47 & $\mathrm{C} 5$ & $\mathrm{AD}$ & $\mathrm{AF}$ & 47 & $\mathrm{C5}$ \\
\hline FA & 59 & C5 & $6 \mathrm{E}$ & 59 & C5 & $6 \mathrm{E}$ & FA \\
\hline 63 & C5 & 63 & 39 & 63 & 39 & 63 & C5 \\
\hline D7 & 67 & $2 \mathrm{~B}$ & FC & FC & D7 & 67 & $2 \mathrm{~B}$ \\
\hline
\end{tabular}

c. MixColumns pada array state digunakan sebagai polynomial yang berada pada GF(28) dan lalu dilakukan perkalian dengan modulo $\mathrm{x} 4+1$, dengan suatu polynomial
Tabel 7. Hasil Transformasi ShiftRows() Sebelumnya

\begin{tabular}{cccc}
\hline $\mathrm{AD}$ & $\mathrm{AF}$ & 47 & $\mathrm{C} 5$ \\
$\mathrm{FA}$ & 59 & $\mathrm{C} 5$ & $6 \mathrm{E}$ \\
63 & $\mathrm{C} 5$ & 63 & 39 \\
$\mathrm{D} 7$ & 67 & $2 \mathrm{~B}$ & $\mathrm{FC}$ \\
\hline
\end{tabular}

d. AddRoundKey melakukan XOR antara round key dengan array state

Tabel 8. Hasil AddRoundkey

\begin{tabular}{|c|c|c|c|c|c|c|c|}
\hline \multicolumn{4}{|c|}{ round key } & \multicolumn{4}{|c|}{ array state } \\
\hline $6 \mathrm{~b}$ & 72 & 73 & 74 & 74 & 92 & $\overline{01}$ & 93 \\
\hline 75 & 61 & 69 & 74 & 69 & F9 & 00 & F9 \\
\hline $6 e$ & 68 & 61 & 69 & $6 \mathrm{~d}$ & $3 \mathrm{C}$ & 00 & $3 C$ \\
\hline 69 & 61 & $6 \mathrm{e}$ & $6 \mathrm{~d}$ & 74 & 92 & 00 & 92 \\
\hline $6 \mathrm{~b}$ & & & & & & & \\
\hline 75 & & & & & & & \\
\hline $6 \mathrm{e}$ & & & & & - & & \\
\hline 69 & & & & & & & \\
\hline
\end{tabular}

\begin{tabular}{llll}
\hline F8 & $8 \mathrm{~A}$ & $\mathrm{~F} 9$ & $8 \mathrm{D}$ \\
8C & ED & 84 & F0 \\
52 & $3 \mathrm{~A}$ & $5 \mathrm{~B}$ & 32 \\
FB & $9 \mathrm{~A}$ & F4 & 99 \\
\hline
\end{tabular}

c. Final round Pada putaran akhir tidak lagi melakukan mixclom melainkan setelah sihiftrow langsung addrounkey hasil seperti Tabel 7.

Tabel 9. Hasil Enkripsi Mengunakan AES

\begin{tabular}{cccc}
\hline \multicolumn{4}{c}{ Chipertex } \\
\hline D5 & 81 & 92 & C5 \\
E6 & A3 & 21 & A2 \\
AF & DF & 6 C & E3 \\
13 & 74 & 95 & 0F \\
\hline
\end{tabular}

Chipertext yang dihasilkan melalui Algoritma AES di jadikan secretkey pada signature token, sehingga token yang dihasilkan sebagai berikut "eyJ0eXAiOiJKV1QiL CJhbGciOiJIUzI1NiJ9.eyJzdWIiOjEyMzQ1Njc4OTAs Im5hbWUiOiJKb2huIERvZSIsImlhdCI6MTUxNjIzOT AyMn0.Dn1t0Q0P_73kiF3qeRXIUUgBMytjuClI3EWi Gw4ifoQ"

\subsection{Hasil Pengujian}

a. Sebelum Implementasi Algoritma AES

Uji coba dengan memasukan script jahat pada form <script>alert(document.cookie) $</$ script $>$ dan hasilnya cookie dengan mudah didapatkan terlihat pada Gambar 7.

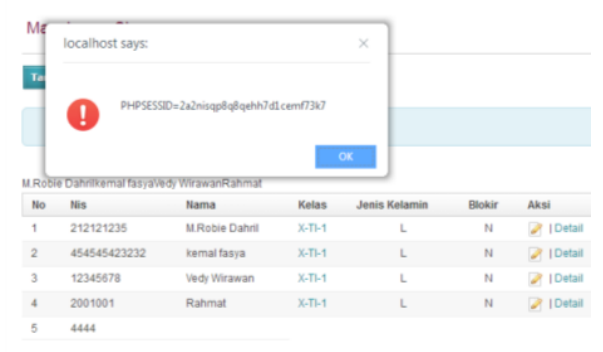

Gambar 7. Uji Coba Memasukan Script Berbahaya Sebelum Implementasi Algoritma AES 
b. Setelah Penerpaan Algoritma AES

Uji coba dengan memasukan script $<$ script $>$ alert(document.cookie) $</$ script $>$ dan hasilnya script tersebut tidak bisa dieksekusi melainkan ditampilkan sesuai karakternya didapatkan terlihat pada Gambar 8.

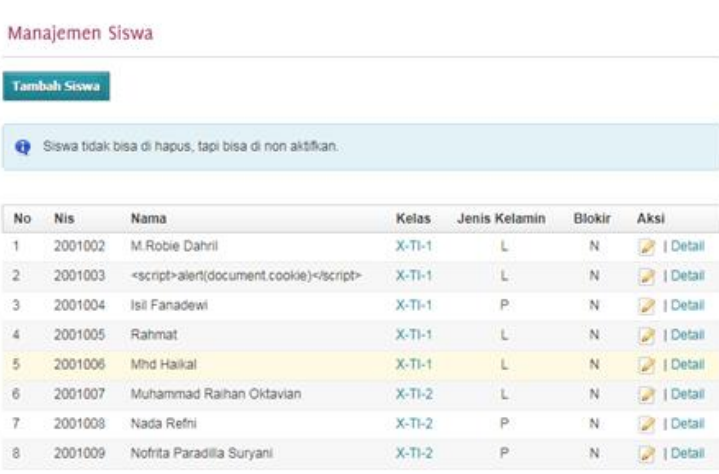

Gambar 8. Uji Coba Memasukan Script Berbahaya Setelah Implementasi Algoritma AES

Selanjutnya dilakukan pengujian menggunakan aplikasi acunetix mendapatkan tingkat kerentanan yang sebelumnya terdapat tingkat kerentanan hight yaitu serangan XSS, dengan penerapan Algoritma AES maka kerentanan yang semula berjumlah 8 (delapan) berkurang menjadi 6 (enam) dan kerentanan kategori hight sudah bisa teratasi, hasil scaning menggunakan Acunetix dapat dilihat pada Gambar 9.

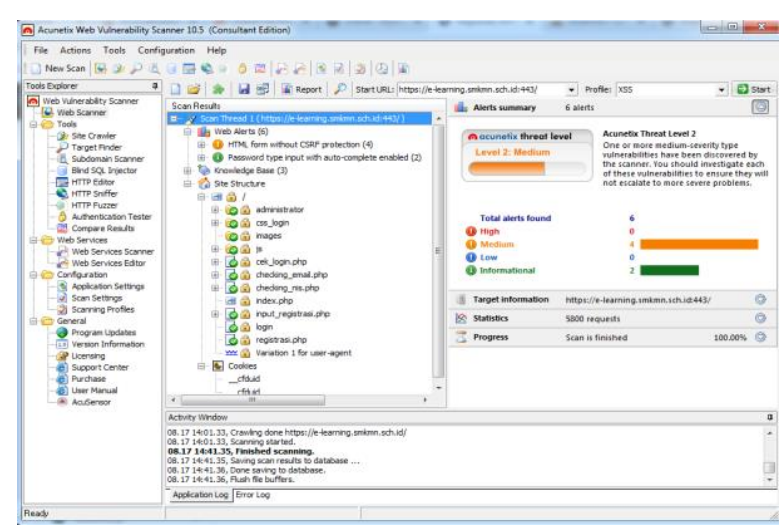

Gambar 9. Hasil Scaning Setelah Implementasi Algoritma AES Mengunakan Aplikasi Acunetix

Agar lebih jelas hasil perbandingan antara sebelum dan setelah Implementasi Algoritma AES dapat dilihat pada Tabel 10

Tabel 10. Perbandigan sebelum dan sesusah impelementasi Algoritma AES

\begin{tabular}{|c|c|c|c|c|c|c|}
\hline \multicolumn{4}{|c|}{ Sebelum Implementasi Algoritma AES } & \multicolumn{3}{|c|}{ Setelah Implementasi Algoritma AES } \\
\hline No & Indikasi File & Kerentanan & $\begin{array}{c}\text { Kategori } \\
\text { Resiko }\end{array}$ & Indikasi File & Kerentanan & $\begin{array}{c}\text { Kategori } \\
\text { Resiko }\end{array}$ \\
\hline 1. & $\begin{array}{l}\text { /input_registrasi.php. } \\
\text { nama }\end{array}$ & Cross site scripting & Hight & $\begin{array}{l}\text { Berhasil } \\
\text { diatasi }\end{array}$ & Berhasil diatasi & $\begin{array}{l}\text { Berhasil } \\
\text { diatasi }\end{array}$ \\
\hline 2. & $\begin{array}{l}\text { /input_registrasi.php } \\
\text { nama }\end{array}$ & Cross site scripting & Hight & $\begin{array}{l}\text { Berhasil } \\
\text { diatasi }\end{array}$ & Berhasil diatasi & $\begin{array}{l}\text { Berhasil } \\
\text { diatasi }\end{array}$ \\
\hline 3. & /administrator. & $\begin{array}{l}\text { HTML form without CSRF } \\
\text { protection }\end{array}$ & Medium & /administrator. & $\begin{array}{l}\text { HTML form without CSRF } \\
\text { protection }\end{array}$ & Medium \\
\hline 4. & /login.php & $\begin{array}{l}\text { HTML form without CSRF } \\
\text { protection }\end{array}$ & Medium & /login.php & $\begin{array}{l}\text { HTML form without CSRF } \\
\text { protection }\end{array}$ & Medium \\
\hline 5. & /registrasi.php & $\begin{array}{l}\text { HTML form without CSRF } \\
\text { protection }\end{array}$ & Medium & /registrasi.php & $\begin{array}{l}\text { HTML form without CSRF } \\
\text { protection }\end{array}$ & Medium \\
\hline 6. & /login.php & $\begin{array}{l}\text { HTML form without CSRF } \\
\text { protection }\end{array}$ & Medium & /login.php & $\begin{array}{l}\text { HTML form without CSRF } \\
\text { protection }\end{array}$ & Medium \\
\hline 7. & /administrator.php & $\begin{array}{l}\text { Password type input with } \\
\text { auto-complete enabled }\end{array}$ & Low & /administrator.ph & $\begin{array}{l}\text { Password type input with } \\
\text { auto-complete enabled }\end{array}$ & Low \\
\hline 8. & /login.php & $\begin{array}{l}\text { Password type input with } \\
\text { auto-complete enabled }\end{array}$ & Low & /login.php & $\begin{array}{l}\text { Password type input with } \\
\text { auto-complete enabled }\end{array}$ & Low \\
\hline
\end{tabular}

\section{Kesimpulan}

Berdasarkan hasil dari penelitian tentang Implementasi Algoritma AES pada token dalam meningkatkan keamanan website dari seragan XSS yang telah dilaksanakan dengan melakukan pengujian mengunakan Aplikasi Acunetix WVS 10.5 pada website https://www.e-learning.smkmn.sch.id. Memberikan informasi diantaranya terdapat 8 (delapan) serangan dengan rincian, 2 (dua) kategori hight dengan nama serangan XSS, 4 (empat) kategori medium dengan nama serangan HTML form without CSRF protection dan 2 (dua) kategori low dengan nama serangan Password type input with auto-complete enabled. Hasil setelah menerapkan Algoritma AES mejelaskan bahwa sebelumnya terdapat 2 (dua) kerentanan kategori hight dengan nama Serangan XSS, setelah implementasi
Algoritma AES maka kerentanan dari serangan XSS dapat diatasi. Algoritma AES mudah untuk diterapkan, memiliki tingkat keamanan yang tinggi serta mengunakan memori yang sedikit dalam pengoperasianya sehingga tidak membebani proses dan ukuran file. Pada pengembangan aplikasi berikutnya agar session disimpan ke dalam database supaya mudah di manajemen.

\section{Daftar Rujukan}

[1] Putra, S. S. H. (2017). Penanggulangan Serangan XSS , CSRF, SQL Injection Menggunakan Metode Blackbox Pada Marketplace IVENMU. Jurnal Pendidikan dan Teknologi Informasi, 4(2), 289-300.

2] Marashdih, A. W., \& Zaaba, Z. F. (2017). Cross Site Scripting: Removing Approaches in Web Application. Procedia Computer

Jurnal Sistim Informasi dan Teknologi Vol. 3 No. 2 (2021) 56-63 
Science, $\quad$ 124, 647-655.

http://doi.org/10.1016/j.procs.2017.12.201 .

[3] Marashdih, A. W., Zaaba, Z. F., \& Omer, H. K. (2017). Web Security: Detection of Cross Site Scripting in PHP Web Application using Genetic Algorithm. International Journal of Advanced Computer Science and Applications (IJACSA), 8(5). DOI: http://doi.org/10.14569/ijacsa.2017.080509 .

[4] Mohammadi, M., Chu, B-T., \& Lipford, H. R. (2018). Automated Detecting and Repair of Cross-Site Scripting Vulnerabilities. Cornell Unversity.

[5] G, K. N., S. Sahana, S., \& Santhosh, K. B. J. (2019). Detection and Avoidance of Web Vulnerability Using XSS. International Journal of Recent Technology and Engineering (IJRTE), 8(2), 1737-1740. DOI: http://doi.org/10.35940/ijrte.B1039.078219 .

[6] Fang, Y., Huang, C., Xu, Y., \& Li, Y. (2019). RLXSS: Optimizing XSS Detection Model to Defend Against Adversarial Attacks Based on Reinforcement Learning. Future Internet, 11(8). DOI: http://doi.org/10.3390/fi11080177 .

[7] Yulianingsih, Y. (2017). Melindungi Aplikasi dari Serangan Cross Site Scripting (XSS) dengan Metode Metacharacter. Journal Nasional Teknologi \& Sistem Informasi, 3(1), 83-88. DOI: http://doi.org/10.25077/teknosi.v3i1.2017.83-88 .

[8] Rahmatulloh, A., Sulastri, H., \& Nugroho, R. (2018). Keamanan RESTful Web Service Menggunakan JSON Web Token (JWT) HMAC SHA-512. Jurnal Nasional Teknologi Elektro dan Teknologi Informasi, 7(2). DOI: http://dx.doi.org/10.22146/jnteti.v7i2.417 .

[9] Aris., Sahara, S., Aini, N., Ajija, M. T., \& Mauna, R. N. (2017). Implementasi Kriptografi Algoritma AES Serta Algoritma Kompresi Huffman dengan Menggunakan Pemograman PHP. Koferensi Nasional Sistem \& Informatika, 2(1), 225-230.
I: [10]Prameshwari, A., \& Sastra, N. P. (2018). Implementasi Algoritma Advanced Encryption Standard (AES) 128 Untuk Enkripsi dan Dekripsi File Dokumen. Jurnal Eksplora $\begin{array}{ll}\text { Informatika, } & 8(1) . \\ \end{array}$ http://doi.org/10.30864/eksplora.v8i1.139.

[11] Anwar, S. (2017). Implementasi Pengamanan Data dan Informasi dengan Metode Steganografi LSB dan Algoritma Kriptografi AES. Jurnal Format, 6(1).

[12] Santoso, K. I., \& Priyoatmoko, W. (2016). Pengamanan Data Mysql pada E-Commerce dengan Algoritma AES 256. Seminar Nasional Sistem Informasi Indonesia, 1(1).

[13] Wiguna, B. S., Kusyanti, A., \& Yahya, W. (2018). Implementasi Algoritme Blake2s pada JSON Web Token (JWT) sebagai Algoritme Hashing untuk Mekanisme Autentikasi Layanan REST-API. JPTIIK Jurnal Pengembangan Teknologi Informasi dan Ilmu Komputer, 2(12), 6269-6276.

[14] Gunawan, R., \& Rahmatulloh, A. (2019). JSON Web Token (JWT) untuk Authentication pada Interoperabilitas Arsitektur berbasis RESTful Web Service. Jurnal Edukasi dan Penelitian $\begin{array}{lll}\text { Informatika (JEPIN), 5(1). } & \end{array}$ http://dx.doi.org/10.26418/jp.v5i1.27232 .

[15]Budianto, W., Amini, S., \& Ariyani, P. F. (2017). Aplikasi Pengamanan Dokumen Digital Menggunakan Algoritma Kriptografi Advanced Encryption Standard (AES-128), Kompresi Huffman Dan Steganografi End of File (EoF) Berbasis Desktop Pada Cv. Karya Perdana. Seminar Nasional Teknologi dan Informatika (Prosiding SNATIF).

[16]Mustika, L. (2020). Implementasi Algoritma AES Untuk Pengamanan Login dan Data Customer Pada E-Commerce Berbasis Web. JURIKOM (Jurnal Riset Komputer), 7(1). DOI: http://dx.doi.org/10.30865/jurikom.v7i1.1943. 